DR. HEROEN VERBRUGGEN (Orcid ID : 0000-0002-6305-4749)

4

5

Article type : Regular Article

9 Widely distributed red algae often represent hidden introductions, complexes of cryptic

species or species with strong phylogeographic structure

Pilar Díaz-Tapia ${ }^{2}$

Coastal Biology Research Group, Faculty of Sciences and Centre for Advanced

Scientific Research (CICA), University of A Coruña, 15071, A Coruña. Spain

School of BioSciences, University of Melbourne, Victoria 3010, Australia

Christine A. Maggs

Portaferry Marine Laboratory, Queen's University Belfast, Belfast BT22 1PF, Northern

Ireland

Erasmo C. Macaya

Laboratorio de Estudios Algales (ALGALAB), Departamento de Oceanografía,

21 Facultad de Ciencias Naturales y Oceanográficas, Universidad de Concepción,

22 Concepción, Chile

23 Millennium Nucleus Ecology and Sustainable Management of Oceanic Island (ESMOI)

24 Centro FONDAP de Investigaciones en Dinámica de Ecosistemas Marinos de Altas

25 Latitudes (IDEAL)

\title{
Heroen Verbruggen
}

This is the author manuscript accepted for publication and has undergone full peer review but has not been through the copyediting, typesetting, pagination and proofreading process, which may lead to differences between this version and the Version of Record. Please cite this article as doi: 10.1111/jpy.12778-18-070

This article is protected by copyright. All rights reserved 
27 School of BioSciences, University of Melbourne, Victoria 3010, Australia

$28 \quad{ }^{2}$ Author for correspondence: e-mail pdiaz@udc.es

29 Running title: Red algae with wide geographical distributions

30 Editorial Responsibility: K. Müller (Associate Editor)

31

ABSTRACT

Despite studies suggesting that most seaweeds are poor dispersers, many red algal species are reported to have circumglobal distributions. Such distributions have mostly been based on morphological identifications, but molecular data have revealed a range of issues with morphologically defined species boundaries. Consequently, the real distribution of such reportedly circumglobal species must be questioned. In this study, we analyzed molecular datasets ( $r b c \mathrm{~L}$ gene) of nine species in the Rhodomelaceae for which samples were available from widely spaced geographical locations. Three overall patterns were identified: 1) species showing strong phylogeographic structure (i.e., phylogenetic similarity correlates with geographical provenance), often to the point that populations from different locations could be considered as different species (Lophosiphonia obscura, Ophidocladus simpliciusculus, Polysiphonia villum and Xiphosiphonia pinnulata); 2) species with a broad distribution that is explained, in part, by putative human-mediated transport (Symphyocladia dendroidea and Polysiphonia devoniensis); and 3) non-monophyletic complexes of cryptic species, most with a more restricted distribution than previously thought (Herposiphonia tenella, S. dendroidea and the X. pennata complex that includes the species X. pinnulata and S. spinifera). This study shows that widely distributed species are the exception in marine red algae, unless they have been spread by humans.

Key words: introductions, new record, phylogeography, Rhodomelaceae, Polysiphonieae, Pterosiphonieae, Herposiphonieae, $r b c \mathrm{~L}$, species boundaries, species complexes

INTRODUCTION 
Phylogeography of marine organisms is influenced by barriers to dispersal and geographical distance, as well as by aspects of their life-history, physiology and ecology (Jackson 1974, Palumbi 1994, Riginos et al. 2011). The dispersal ability of seaweeds is generally very limited, of the order of tens of meters or less (Santelices 1990, Kinlan and Gaines 2003, Destombe et al. 2009). However, long-distance dispersal is known in brown seaweeds with buoyant structures (Fraser et al. 2009, Macaya and Zuccarello 2010), which can act as rafts promoting in turn the dispersal of the epiphytic species that they host (Fraser et al. 2013, Macaya et al. 2016, López et al. 2017, 2018). Still, a large proportion of macroalgae are epilithic, so their expected dispersal ability is very limited and consequently their distribution range is expected to be relatively small. Paradoxically, many macroalgal species are reported to be very widely or even globally distributed.

Records are usually based only on morphological identification, which can be inaccurate due to morphological plasticity within species as well as similarity between cryptic species (e.g., Verbruggen 2014, Schneider et al. 2017). Closer investigation of material from distant regions using DNA data commonly leads to the discovery of cryptic species (e.g., Won et al. 2009, Bustamante et al. 2014, Schneider et al. 2017). Even though studies combining morphological and molecular data are increasing, DNA databases are still very limited for most algal groups and molecular data are often available only for some regions. As a consequence, the true distribution of many seaweed species should be regarded as uncertain. Few studies have reassessed the distribution of widely reported red algal species using molecular data from a broad sampling area. Complexes of look-alike species, as well as widely distributed species, have been detected (Zuccarello et al. 1999, Zuccarello et al. 2002a, Zuccarello and West 2003, Won et al. 2009). Among the widely distributed species, some exhibit high genetic variability and strong phylogeographic structure that often distinguishes populations from different basins (Zuccarello et al. 2002a,b, Won et al. 2009). Other widely distributed species lack phylogeographic signal, suggesting long-distance dispersal processes by unknown mechanisms (Zuccarello et al. 2002a, Fraser et al. 2013). Therefore, red algal phylogeographic patterns are highly heterogeneous and depend on evolutionary histories and dispersal abilities.

In addition to natural dispersal mechanisms, human-mediated vectors can transport seaweeds from native areas to other world regions and rapidly alter distribution patterns 
(Straub et al. 2016). More than 208 red algal species have been considered as introduced or cryptogenic in one or several regions (Thomsen et al. 2016). Cryptic introductions are common in the red algae and non-native species often remain unnoticed until diversity surveys use molecular tools (McIvor et al. 2001, Zuccarello et al. 2002b, DíazTapia et al. 2013b, 2017a). Considering the low dispersal ability of non-buoyant epilithic red algae, we hypothesize that the distribution of most truly cosmopolitan species can be explained by human-mediated transport - which is frequently provided as a potential explanation for wide distributions of species (Zuccarello et al. 2002a,b, Fraser et al. 2013).

The Rhodomelaceae, with >1,000 recognized species, is the most diverse red algal family (Guiry and Guiry 2018). It includes numerous examples of widely reported species and, as in most red algal groups, cryptic diversity is common (e.g., Zuccarello et al. 2002a, Díaz-Tapia and Bárbara 2013, Bustamante et al. 2014, Savoie and Saunders 2016, Zuccarello et al. 2018). Among the red algae the Rhodomelaceae accounts for the largest number of introduced species (Williams and Smith 2007). Members of this family are often major components of algal turfs where canopy-forming brown algae with buoyant structures are rare as a consequence of the stressful conditions imposed by the presence of sediment (Airoldi 1998, Díaz-Tapia et al. 2013a). This makes the family a good candidate to test hypotheses about species distributions and phylogeographic patterns.

The objective of this paper is to reassess the wide reported distributions of nine turfforming species of the family Rhodomelaceae using DNA sequences. Using molecular data from distant locations within each species' reported distribution range, we evaluate whether these are indeed widely distributed species, analyze the observed phylogeographic patterns, and consider whether these species may have been introduced into one or several regions by human activities.

\section{MATERIALS AND METHODS}

Material of Herposiphonia tenella, Lophosiphonia obscura, Ophidocladus simpliciusculus, Polysiphonia villum, P. devoniensis, Symphyocladia spinifera, S. dendroidea, Xiphosiphonia pennata and X. pinnulata was collected in Norway, United 

during general sampling surveys of the family Rhodomelaceae (Table S1 in the Supporting Information). All these species form epilithic turfs, most of them on intertidal sand-covered rocks (Womersley 2003, Díaz-Tapia and Bárbara 2013). Lophosiphonia obscura was found in North Atlantic brackish water coastal lagoons or estuaries, and Symphyocladia dendroidea was collected in Australian and Chilean shallow subtidal turfs. Distribution maps of records for these species (Figs. 1-3, lines) were drawn up based on information available in AlgaeBase and references therein (Guiry and Guiry 2018).

DNA was extracted from silica gel-dried material following Saunders and McDevit (2012), using the Qiagen DNeasy Plant Mini Kit (Qiagen GmbH, Hilden, Germany) or the Promega Wizard Magnetic 96 DNA Plant System kit (Promega Corporation, Madison, USA), following the manufacturer's instructions. PCR amplification was carried out for the $r b c \mathrm{~L}$ gene using primers F7/RrbcStart, F7/R893 or F57/rbcLrevNEW (Freshwater and Rueness 1994, Mamoozadeh and Freshwater 2011, Saunders and Moore 2013), as well as the newly designed primers F2 (TGTCTAACTCTGTAGAACAACGGA), F8 (ACTCTGTAGAASAACGGACAMG), R1008 (AACTACTACAGTACCAGCATG), R1464 (AACATTAGCTGTTGGAGTTTCYAC) and R1452 (TGGAGTTTCYACRAAGTCAGCTGT). Names of these primers indicate their position in the $r b c \mathrm{~L}$ gene (e.g., first base of $\mathrm{F} 2$ primer corresponds with the second base of the $r b c \mathrm{~L}$ gene). PCR reactions were performed in a total volume of $25 \mu$ l containing $1 \times$ MyTaqTM reaction buffer, $0.28 \mu \mathrm{M}$ of forward and reverse primers, 0.125 units My TaqTM DNA Polymerase (Bioline, London, UK) and $1 \mu 1$ template DNA. The PCR profile consisted of initial denaturation $\left(93^{\circ} \mathrm{C}\right.$ for $\left.3 \mathrm{~min}\right), 35$ cycles of denaturation $\left(94^{\circ} \mathrm{C}\right.$ for $\left.30 \mathrm{~s}\right)$, primer annealing $\left(45^{\circ} \mathrm{C}\right.$ for $\left.30 \mathrm{~s}\right)$, and extension $\left(74^{\circ} \mathrm{C}\right.$ for $\left.90 \mathrm{~s}\right)$ and final extension $\left(74^{\circ} \mathrm{C}\right.$ for $\left.5 \mathrm{~min}\right)$. The PCR products were purified and sequenced at Queen's University of Belfast on an AB3730xl DNA Analyzer (Applied Biosystems, Foster City, CA, USA) or commercially by Macrogen or the sequencing service of the University of A Coruña.

A total of 128 new $r b c \mathrm{~L}$ sequences were generated in this study and an additional 91 sequences were downloaded from GenBank (Table S1). Length of sequences ranged from 585 to 1467 (Table S1). Sequences were aligned using Muscle in Geneious 6.1.8 (Kearse et al. 2012). As a first stage, we analyzed these sequences in taxon-rich datasets 
for the tribes Herposiphonieae, Pterosiphonieae, Polysiphonieae and Streblocladieae to verify that the target species were monophyletic. Based on the resulting trees, we selected all sequences corresponding to the species (or group of closely related species) that are the focus of this paper. These datasets were analyzed species by species using the unweighted pair group method with arithmetic mean (UPGMA). For two complexes of non-sister species in our initial taxon-rich trees (Symphyocladia dendroidea and Herposiphonia tenella), we included wider species sampling considering the available data for the respective genera (Table S1). We performed maximum likelihood (ML) analyses separately for each of the two genera using RAxML 8.1.X (Stamatakis 2014). GTR-Gamma was used as the nucleotide model and branch support was estimated with 1000 bootstrap replicates. Three species of Xiphosiphonia and Dipterosiphonia were selected as the respective outgroups for the Symphyocladia and Herposiphonia trees based on our phylogenomic analyses of the major lineages of the Rhodomelaceae (DíazTapia et al. 2017b).

\section{RESULTS}

The taxonomy of several of the studied species is complex and details are provided in Appendix S1 in the Supporting Information.

\section{Ophidocladus simpliciusculus}

Ophidocladus simpliciusculus was collected in four out of the six world regions where it has been reported (Fig. 1a). The UPGMA analyses included 15 newly determined $r b c \mathrm{~L}$ sequences and two downloaded from GenBank (Table S1). Sequences comprised four haplotypes (Fig. 1b): haplotype 1, seven samples from Europe (Atlantic and Mediterranean); haplotype 2, six samples from Australia; haplotype 3, one sample from South Africa; and haplotype 4, three samples from Brazil. The South African sample differed by only $0.1 \%$ (1 bp) from the Australian samples, while Brazilian samples were the most divergent (up to $0.8 \%$ and $11 \mathrm{bp}$ ) from samples from other regions. Our results indicate that $O$. simpliciusculus has a unique $r b c \mathrm{~L}$ haplotype in each region, but it has a strong phylogeographic structure.

\section{Lophosiphonia obscura}


Lophosiphonia obscura has been reported in the Atlantic and Indo-Pacific and sequences are available from Europe and Australia (Fig. 1c). Furthermore, our dataset also included Polysiphonia hemisphaerica from Norway and P. boldii from Texas, USA which may be conspecific as suggested by the low $r b c$ L divergence with $L$. obscura (see Appendix S1). We analyzed six newly determined $r b c \mathrm{~L}$ sequences and two downloaded from GenBank for Lophosiphonia obscura, Polysiphonia hemisphaerica and P. boldii (Table S1). Four haplotypes were found (Fig. 1d): 1) four samples from Spain (Atlantic and Mediterranean) and Norway; 2) a sample from the United Kingdom; 3) a sample from USA; and 4) two samples from Australia. Atlantic samples differed by 0.1-0.2\% (1-2 bp), while Australian samples were 0.7-0.9\% (8-11) divergent from the Atlantic samples. Our results indicate that the lineage formed by these three taxa is moderately variable in the North Atlantic, and is clearly separated from the Australian populations.

\section{Polysiphonia villum}

Molecular data were obtained from two regions where Polysiphonia villum (as $P$. scopulorum var. villum, see Appendix S1) had previously been reported (Fig. 1e). Furthermore, it was also sampled in Spain, the French Mediterranean and Australia, where it is here newly recorded. The 13 sequences determined for $P$. villum and the two downloaded from GenBank (Table S1) belong to three haplotypes (Fig. 1f): 1) four samples from Australia, 2) three samples from Brazil and 3) eight samples from the North Atlantic (North Carolina, Spain and France). Australian samples were 0.5-0.6\% (4-7 bp) divergent from the Atlantic samples and the Brazilian sequences differed by $0.2 \%$ ( $2 \mathrm{bp}$ ) from the North Atlantic samples. Thus, $P$. villum shows a clear phylogeographic structure.

\section{Polysiphonia devoniensis}

Our dataset included samples from the previously recorded distribution in Atlantic Europe, as well as from the northwestern Mediterranean (Italy and France), the Adriatic Sea (Italy) and Victoria (Australia), from where P. devoniensis is here recorded for the first time (Fig. 2a, Table S1). Furthermore, sequences of $P$. kapraunii from North Carolina were also included in our dataset (see Appendix S1). Analyses including an 
$r b c \mathrm{~L}$ sequence of $P$. kapraunii from GenBank and 21 newly determined sequences of $P$. devoniensis (Table S1) showed eight haplotypes (Fig. 2b). One haplotype was found in the northwestern Mediterranean, Atlantic Spain and Australia; one occurred in the Adriatic Sea and the northwestern Mediterranean; and six haplotypes were each represented by a single sample (two from Wales, two from the Adriatic Sea, one from the northwestern Mediterranean and one from North Carolina). The North Carolina sample identified as P. kapraunii was $0.2-0.3 \%$ (3-4 bp) divergent from two of the European samples (PD301 and PD2430). These three samples differ from the others by sequence divergences of $1-1.4 \%$ (12-18 bp), while divergence between the other five haplotypes is $0.1-1 \%$ (1-9 bp). The lineage formed by samples assigned to $P$. devoniensis and $P$. kapraunii has a high genetic diversity and the distribution of haplotypes lacks geographic structure.

\section{Symphyocladia dendroidea complex}

Sequences of Symphyocladia dendroidea are available from most of the previously known distribution (British Columbia, California, Chile, Peru, Japan and the Mediterranean). Some of these sequences were labelled as Pterosiphonia tanakae (see Appendix S1). Furthermore, we collected this species in a Galician marina (northwestern Spain) and in Australia (Victoria), where it is here recorded for the first time (Fig. 2c).

The rbcL data for Symphyocladia dendroidea reveal cryptic diversity in the Americas, as specimens from Peru and Chile and specimens from British Columbia (here referred as S. dendroidea 2) do not constitute a clade (Fig. S1 in the Supporting Information, Table S1). In addition to these regions, both were recorded in California. Symphyocladia dendroidea is resolved as sister to $S$. parasitica with high support, while S. dendroidea 2 is placed in a moderately supported clade together with S. brevicaulis and S. baileyi (Fig. S1). Molecular data show that $S$. dendroidea has a wide distribution in the Pacific and occurs in some European locations, while S. dendroidea 2 is apparently restricted to Pacific North America.

In total, $28 \mathrm{rbcL}$ sequences were analyzed for Symphocladia dendroidea (some sequences labelled as S. tanakae, see Appendix S1) including 13 newly determined and 15 downloaded from GenBank (Table S1). The UPGMA dendrogram shows seven 
haplotypes (Fig. 2d) of which five comprise samples from Pacific South America, one includes samples from Australia and Japan, and the other consists of samples from California and Europe. Maximum variability between South American haplotypes is $0.6 \%$ ( $8 \mathrm{bp}$ ), and sequence divergence between them and the two other clades is $0.4-1 \%$ (3-9 bp). These levels of $r b c \mathrm{~L}$ variation suggest that this entity may consist of multiple species or highly differentiated populations.

Xiphosiphonia pennata complex, including X. pinnulata and Symphyocladia spinifera Xiphosiphonia pennata has been reported in the Atlantic and Indo-Pacific (Fig 2e) and this morphological species is a complex of at least three non-sister species. Their taxonomy has been resolved with the clarification of the identity of $X$. pinnulata and $S$. spinifera that have been misidentified as X. pennata (see Appendix S1).

At present, $39 r b c \mathrm{~L}$ sequences (16 newly determined and 23 downloaded from GenBank) are available for Symphyocladia spinifera from California, Pacific South America, Australia and Korea (Fig. 2f). The UPGMA shows 10 haplotypes of which four correspond to Korean samples, four to Peruvian samples, one to Australian samples and one to a Washingtonian sample (Fig. 2f). Sequence divergence among haplotypes is up to $0.9 \%(7 \mathrm{bp})$. Australian samples match the morphological concept of Xiphosiphonia pennata, but our molecular data reveal that none of them grouped with the European $X$. pennata but instead are mostly closely related to S. spinifera. Therefore, $X$. pennata should be excluded from the recorded Australian flora and replaced by $S$. spinifera. Interestingly, all the Australian samples belong to a single haplotype, which contrasts with the four haplotypes found in both Peru and Korea.

Xiphosiphonia pinnulata sequences were resolved as three haplotypes of which two were found in European samples and one in Brazilian samples (Fig. 2g). Sequence divergence among them is up to $0.7 \%(9 \mathrm{bp})$ and between the two European clades is up to $0.3 \%$ (3 bp). X. pennata was only found in the Atlantic Iberian Peninsula. Therefore, the widely reported $X$. pennata (as Pterosiphonia pennata) is apparently restricted to European shores. X. pinnulata is restricted to the Atlantic, where it has a strong phylogeographic structure with divergences that may even suggest they are separate species. S. spinifera is restricted to the Pacific and it has a high genetic variability between regions and within regions in Korea and South America. 
282 In total, $27 r b c \mathrm{~L}$ sequences were obtained for samples morphologically identified as

283 Herposiphonia tenella from Europe, North America and Queensland (Australia; Fig. 3).

284 They were analyzed together with the available $r b c \mathrm{~L}$ data for the genus (15 species).

285 The phylogeny resolved H. tenella in seven lineages, four from the Atlantic and three

286 from Queensland (Fig. 4). Sequence divergence among the lineages was at least 1.9\%,

287 while divergence within them was up to $0.7 \%$. Only two of these lineages were resolved

288 as sisters (1.9-2.1\% sequence divergence), while the others, despite morphological

289 similarities, were more closely related to other lineages. Thus, Herposiphonia tenella is

290 a large species complex that requires taxonomic revision to better understand its cryptic

291 diversity and the distribution of the resulting new species. Its type locality is in the

292 Mediterranean, where three of the four European lineages were collected.

293

294

\section{DISCUSSION}

295

Species complexes

296

In this work we detected several complexes of non-sister species (Xiphosiphonia pennata, Symphyocladia dendroidea and Herposiphonia tenella). Also, we found species-level taxa that represent monophyletic lineages containing several haplotypes that in most cases are distributed in accordance with geographic regions. They could also be classified as species complexes, as sequence divergences between haplotypes are often large (up to 1.4\%), possible evidence for multiple species. Interpretations of genetic divergences when delineating species boundaries vary among authors. For example, Melanothamnus harveyi/japonicus and other closely related species have been interpreted as a single species with an intraspecific variability in the $r b c \mathrm{~L}$ gene $\leq 2.1 \%$ (McIvor et al. 2001, as Polysiphonia) or as a species complex in which interspecific variability in the $r b c \mathrm{~L}$ gene is 0.3-0.7 \% (Savoie and Saunders 2015, as Neosiphonia). The species concept has been hotly debated, but there is a general consensus that speciation is a process that takes place when gene flow is interrupted as a consequence of isolation of populations (Coyne et al. 1988, Leliaert et al. 2014). In the present work, assessing species boundaries was not always straightforward, and we used information based on genetic divergences, species distribution and, in one lineage, interbreeding 
experiments described by Rueness (1973). The first scenario we encountered consists of species with a variety of haplotypes found in distant locations. Genetic isolation by distance seems obvious considering our data and, in some cases, where the divergences between distant populations are relatively large $(\leq 0.9 \%)$, one might consider them different species (Ophidocladus simpliciusculus from Europe vs. Brazil vs. Australia/South Africa, Lophosiphonia obscura from the North Atlantic vs. Australia, Polysiphonia villum from the Atlantic vs. Australia, and Xiphosiphonia pinnulata from Brazil vs. Europe). However, the low number of samples in some regions or species, as well as the lack of sampling in other regions where these species were recorded or may be still unknown precludes a definitive conclusion. Perhaps the observed large sequence divergences between the lineages within these species would be less evident with larger datasets. A seeond scenario is similar to the former, as it consists of species with a variety of haplotypes, but in this case several haplotypes share the same distribution $(P$. devoniensis, Symphyocladia dendroidea, S. spinifera). Thus, despite $r b c \mathrm{~L}$ divergences among some haplotypes $(\leq 1.4 \%)$ being even larger than in the previous group $(\leq$ $0.9 \%)$, whether they are at present reproductively isolated and should be considered as distinct species is uncertain. Interbreeding experiments may assist to clarify if these multiple interpretations (Leliaert et al. 2014), unsuccessful reproduction indicates reproductive incompatibility. The third scenario we found in this work is represented by Lophosiphonia obscura whose eastern and western Atlantic populations have low genetic distances $(0.1-0.2 \%)$ in the $r b c \mathrm{~L}$ gene, and also in the more variable cox 1 marker (0.6-1.2 \%, HQ412544-5 as P. hemisphaerica and P. boldii, MF094025). Despite this, crossing experiments demonstrate that isolates from Texas and from Norway fail to produce fully fertile progeny (Rueness 1973, as $P$. hemisphaerica and $P$. boldii). This suggests that these two populations are reproductively isolated, and that divergent selection may be acting on these populations but $r b c \mathrm{~L}$ and $\operatorname{cox} 1$ gene sequences do not reflect this isolation (Nosil et al. 2009). These three scenarios show different evolutionary patterns even among closely related species (e.g., P. villum vs. $P$. devoniensis). Therefore, application of genetic distances in delineating species boundaries should be evaluated on a case by case basis. While these are very interesting issues from a taxonomic perspective, they are not the focus of this paper. From a phylogeographic point of view, whether these closely related monophyletic lineages are 
different species or not is of minor importance, because either way they share a common ancestor from which several genetic entities evolved.

\section{Phylogeographic patterns}

The paradox between expected dispersal limitation (Santelices 1990, Kilan and Gaines 2003) and wide reported species distributions led us to hypothesize that such widely distributed species would either have strong phylogeographic structure or were spread by humans. Our results confirmed these hypotheses and exposed a third scenario, where the morphologically defined species was in fact a complex of non-sister cryptic species.

Three of the species exhibit genetic variability with clear phylogeographic structure in Australia, and the North and South Atlantic (Ophidocladus simpliciusculus, Lophosiphonia obscura and Polysiphonia villum). This result is not unexpected considering that genetic divergence is promoted by the isolation among populations separated by large geographic distances (Palumbi 1994). However, the observed genetic divergence is relatively low $(\leq 0.9 \%)$ considering that Australia and the North and South Atlantic have been separated since about 80 My (Jordan et al. 2016). Therefore, rather than this genetic divergence resulting from an 80 My old vicariant evolution, long-distance dispersal processes acting on a common ancestor and subsequent divergence into differentiated populations are invoked to explain the observed patterns. Mechanisms responsible for this long-distance dispersal are obscure considering that these species either occur in coastal lagoons/estuaries or on sand-covered rocks where buoyant macroalgae that can act as rafts are rare (Airoldi 1998, Díaz-Tapia et al. 2013a). Molecular data have provided evidence for long-distance dispersal in other red algal species but mechanisms remain unknown (Zuccarello et al. 2002a, Fraser et al. 2013). The genetic separation among geographically distant lineages may indicate that long-distance dispersal occurs at a low rate. Alternatively, density-dependent processes are involved and once a population colonizes a new region it prevents the establishment of latecomers (Waters et al. 2013). Furthermore, available data for the three species mentioned above indicate different evolutionary histories and/or dispersal paths. For instance, in L. obscura and P. villum the largest sequence divergences are between Australian and Atlantic populations, whereas in O. simpliciusculus the Australian 
haplotype is relatively close to South African and European haplotypes but the divergence across the Atlantic (Brazil vs. Europe) is much larger.

Several species showed a diversity of haplotypes sharing the same region: the Pacific Symphyocladia spinifera and S. dendroidea, as well as the Atlantic Polysiphonia devoniensis. The origin of this diversity must be related to processes of isolation that led to genetic differentiation, followed by local dispersal events. As for Ophidocladus simpliciusculus, Lophosiphonia obscura and Polysiphonia villum, dispersal mechanisms for S. spinifera and P. devoniensis are unknown. In contrast, S. dendroidea has been reported growing on stranded holdfasts of the floating alga Durvillaea antarctica (Macaya et al. 2016, López et al. 2017, 2018), which could contribute to dispersal after genetic differentiation influenced its genetic structure.

The disjunct distribution of a second group of species (Polysiphonia devoniensis and Symphyocladia dendroidea) can be explained by human-mediated introduction events. The human transport of species from native (donor) to introduction (recipient) regions causes the rapid expansion of species' distribution and alters natural phylogeographic patterns (Straub et al. 2016). The discovery of $P$. devoniensis in Victoria (Australia), exhibiting a single haplotype that is also present in Europe, suggests that this species has been introduced into this country from Europe, possibly Atlantic Spain or the NW Mediterranean. Symphyocladia dendroidea was recorded as an introduced species in the French Mediterranean in 2005 (Boudouresque and Verlaque 2008, as $P$. tanakae) and our recent discovery of the same haplotype in a marina in Atlantic Spain probably represents a secondary introduction and suggests that the species is spreading in Europe via hull fouling. The presence of several genetically separated lineages of $S$. dendroidea in Pacific South America contrasts with the occurrence of a single haplotype in Japan, Australia and California. Japan and Australia have the same haplotype, suggesting that one or both populations could be introduced. Genetic diversity of seaweeds in the introduced regions is either similar or reduced relative to the native area (McIvor et al. 2001, Voisin et al. 2005, Provan et al. 2008, Geoffroy et al. 2016). The finding of diverse haplotypes in the introduced region is indicative of an introduction involving several haplotypes or multiple introductions, depending on the phylogeographic structure in the native area (McIvor et al. 2001, Voisin et al. 2005, Geoffroy et al. 2016). A single haplotype of both S. dendroidea and $P$. devoniensis has been detected in the areas where the introduction of these species is 
certain, suggesting that their introduction is the result of a single event in which a single haplotype was involved. However, much more complex scenarios could explain the observed patterns and a better understanding of the phylogeographic patterns in native and introduced areas would be needed to elucidate the introduction dynamics.

The third group of species analyzed here involved species complexes of non-sister cryptic species (Xiphosiphonia pennata including X. pinnulata and Symphyocladia spinifera; S. dendroidea; and Herposiphonia tenella). In both cases species found in the Atlantic and Pacific basins differ, but in addition several species were found with overlapping distributions in some regions of each basin. Therefore, the distribution of these widely reported species is much narrower than previously thought. Cryptic algal species often involve a group of morphologically similar species that are genetically differentiated, but resolve as a monophyletic group (Zuccarello et al. 2002a, Won et al. 2009, Payo et al. 2013). However, examples of non-monophyletic cryptic "species" have also been documented in the red algae (Zuccarello et al. 2018). Morphological similarity among non-monophyletic groups of cryptic species can be explained by evolutionary convergence, morphological stasis or developmental constraints (Leliaert et al. 2014, Zuccarello et al. 2018). X. pennata, S. spinifera and S. dendroidea are placed in a tribe (Pterosiphonieae) with high morphological variation ranging from filiform to foliose species (Díaz-Tapia et al. 2017b). The body plan of both species is filiform, among the simplest observed in the tribe, and morphological stasis is a plausible explanation for their similarity. In the tribe Herposiphonieae all species are very similar in morphology, with limited differences in their body plans (Díaz-Tapia et al. 2017b) and the cryptic diversity in Herposiphonia tenella might result from morphological stasis or developmental constraints.

Understanding the processes underlying phylogeographic patterns requires the study of numerous specimens from across the entire distribution of the species. In this regard, we recognize important limitations in our work that prevent us from fully elucidating causes of the observed phylogeographic patterns, leading to some tentative conclusions about the potentially introduced status of some of the analyzed populations. However, most of the species treated here are rare in all or part of their known distribution range so improving the datasets would be very difficult. For example, Lophosiphonia obscura, despite being widely reported, is very rare in the regions here studied: the sample from the UK used in this study is the first one collected since 1970 
442 (Maggs and Hommersand 1993). In Spain, we found it only once in the Atlantic and once in the Mediterranean, and the species is here recorded for only the third time in

444 Australia. Our work should thus be interpreted as one of the first attempts to understand phylogeographic patterns of widely distributed red algal species. Even though their evolutionary history is not well known, our analyses provide clear examples of 1) species with wide distributions and strong phylogeographic structure that reflects the geographical distance; 2) species with a broad distribution that can be only explained by human-mediated transport; and 3) species complexes in which non-monophyletic cryptic diversity has been found. This study indicates that widely distributed species are the exception in red algae, except when they have been spread by humans.

\section{Acknowledgements}

We thank Francis Bunker, Fabio Rindi, Iara Chapuis, Jan Rueness and Max Hommersand for providing samples and Joana Costa, as well as other researchers included in Table S1, for assistance in the field. We thank Marisa Pasella for carrying out part of the molecular work. PDT acknowledges support by the postdoctoral program “Axudas de apoio á etapa de formación posdoutoral”, as well as the funding program "Axudas para a consolidación e estruturación de unidades de investigación competitivas do SUG”, grant GPC2015/025 (Xunta de Galicia). Field work in the Mediterranean Sea was funded by a grant awarded to PDT by the British Phycological Society. Part of the research presented here was funded through the Australian Biological Resources Study (ABRS), including participation in a Bush Blitz expedition, a Bush Blitz Strategic Taxonomy Grant (TTC216-03) and a National Taxonomy Research Grant (RFL21308). Sampling in Western Australia, Queensland and Tasmania was made possible through funding from the Holsworth Wildlife Research Endowment. ECM acknowledges support by the Chilean Millennium Initiative (NC120030) grant.

\section{References}

Airoldi, L. 1998. Roles of disturbance, sediment stress, and substratum retention on spatial dominance in algal turf. Ecology 79:2759-70. 
472 Boudouresque, C. F. \& Verlaque, M. 2008. Biological pollution in the Mediterranean

473 Sea: invasive versus introduced macrophytes. Mar. Pollut. Bull. 44:32-8.

474 Bustamante, D.E., Won, B.Y. \& Cho, T.O. 2014. Polysiphonia dokdoensis sp. nov.

475 (Rhodomelaceae, Ceramiales) based on a population previously known as Polysiphonia 476 atlantica sensu Kim and Lee from Korea. Bot. Mar. 57:281-9.

477 Coyne, J.A., Orr, H.A., \& Futuyma, D.J. 1988. Do we need a new species concept? 478 Syst. Biol. 37:190-200.

479 Destombe, C., Godin, J., Lefebvre, C., Dehorter, O., Vernet, Ph. 2009. Differences in 480 dispersal abilities of haploid and diploid spores of Gracilaria verrucosa (Gracilariales, 481 Rhodophyta). Bot. Mar. 35:93-8.

482 Díaz-Tapia, P. \& Bárbara, I. 2013. Seaweeds from sand-covered rocks of the Atlantic 483 Iberian Peninsula. Part. 1. The Rhodomelaceae (Ceramiales, Rhodophyta). Cryptog. 484 Algol. 34:325-422.

485 Díaz-Tapia, P., Bárbara, I. \& Díez, I. 2013a. Multi-scale spatial variability in intertidal 486 benthic assemblages: Differences between sand-free and sand-covered rocky habitats, 487 Estuar. Coast. Shelf Sci. 133:97-108.

488 Díaz-Tapia, P., Kim, M.S., Secilla, A., Bárbara, I., Cremades, J. 2013b. Taxonomic 489 reassessment of Polysiphonia foetidissima (Rhodomelaceae, Rhodophyta) and similar 490 species, including P. schneideri, a newly introduced species in Europe. Eur. J. Phycol. 491 $48: 345-62$.

493

Díaz-Tapia, P., Bárbara, I., Cremades, J., Verbruggen, H. \& Maggs C.A. 2017a. Three new cryptogenic species in the tribes Polysiphonieae and Streblocladieae (Rhodomelaceae, Rhodophyta). Phycologia 56:605-23. chloroplast genomes and a supermatrix inform reclassification of the Rhodomelaceae (Rhodophyta). J. Phycol. 53:920-37. of subantarctic sea ice during the Last Glacial Maximum. Proc. Natl. Acad. Sci. USA 500 106:3249-53. 
501 Fraser, C.I., Zuccarello, G.C., Spencer, H.G., Salvatore, L.C., Garcia, G.R. \& Waters,

502 J.M. 2013. Genetic affinities between trans-oceanic populations of non-buoyant 503 macroalgae in the high latitudes of the southern hemisphere. PLOS ONE 8:e69138.

504 Freshwater, D.W. \& Rueness, J. 1994. Phylogenetic relationships of some European

505 Gelidium (Gelidiales, Rhodophyta) species based upon $r b c \mathrm{~L}$ nucleotide sequence 506 analysis. Phycologia 33:187-94.

507 Geoffroy, A., Destombe, C., Kim, B, Mauger, S., Raffo, M.P., Kim, M.S. \& Le Gall, L. 508 2016. Patterns of genetic diversity of the cryptogenic red alga Polysiphonia morrowii 509 (Ceramiales, Rhodophyta) suggest multiple origins of the Atlantic populations. Ecol. 510 Evol. 6:5635-47.

511 Guiry, M.D. \& Guiry, G.M. 2018. AlgaeBase; World-Wide Electronic Publication, 512 National University of Ireland: Galway, UK, 2018; Available online:

513 http://www.algaebase.org (accessed on 6 January 2018).

514 Jackson, J.B.C. 1974. Biogeographic consequences of eurytopy and stenotopy among 515 marine bivalves and their evolutionary significance. Amer. Nat. 108:541-60.

516 Jordan, S.M.R., Barraclough T.G. \& Rosindell, J. 2016. Quantifying the effects of the 517 break up of Pangaea on global terrestrial diversification with neutral theory. Phil. Trans. 518 R. Soc. B 371:20150221.

519 Kearse, M., Moir, R., Wilson, A., Stones-Havas, S., Cheung, M., Sturrock, S., Buxton, 520 S, Cooper, A., Markowitz, S., Duran, C., Thierer, T., Ashton, B., Meintjes, P. \& Drummond, A. 2012. Geneious Basic: An integrated and extendable desktop software platform for the organization and analysis of sequence data. Bioinformatics 28:1647-9.

523 Kinlan, B.P. \& Gaines, S.D. 2003. Propagule dispersal in marine and terrestrial 524 environments: a community perspective. Ecology 84:2007-20.

525 Leliaert F., Verbruggen H., Vanormelingen P., Steen, F., López-Bautista J.M., 526 Zuccarello, G.C. \& De Clerck O. 2014. DNA based species delimitation in algae. Eur. 527 J. Phycol. 49: 179-96.

528 López, B.A., Tellier, F., Retamal-Alarcón, J.C., Pérez-Araneda, K., Fierro, A.O., 529 Macaya, E.C., Tala, F. \& Thiel, M. 2017. Phylogeography of two intertidal seaweeds, 
530 Gelidium lingulatum and G. rex (Rhodophyta: Gelidiales), along the South East Pacific: 531 patterns explained by rafting dispersal? Mar. Biol. 164:188.

532 López, B.A., Macaya E. C., Rivadeneira M., Tala F., Tellier F. \& Thiel M. 2018.

533 Epibiont communities on stranded kelp rafts of Durvillaea Antarctica (Fucales,

534 Phaeophyceae) - do positive interactions facilitate range extensions? J. Biogeogr.

$535 \quad 45: 1833-45$.

536 Macaya, E.C. \& Zuccarello, G.C. 2010. Genetic structure of the giant kelp Macrocystis 537 pyrifera along the southeastern Pacific. Mar Ecol Prog Ser 420:103-12.

538 Macaya, E.C.,López, B., Tala, F., Tellier, F. \& Thiel, M. 2016. Float and raft: role of 539 buoyant seaweeds in the phylogeography and genetic structure of non-buoyant 540 associated flora. In Hu, Z.M. \& Fraser, C.I. [Eds.] Seaweed phylogeography. Springer, 541 Dordrecht, pp.97-130.

542 Maggs, C.A. \& Hommersand, M.H. 1993. Seaweeds of the British Isles. Volume 1.

543 Rhodophyta. Part 3A. Ceramiales. HMSO, London, 444 pp.

544 Mamoozadeh, N.R. \& Freshwater, D.W. 2011. Taxonomic notes on Caribbean

545 Neosiphonia and Polysiphonia (Ceramiales, Florideophyceae): five species from 546 Florida, USA and Mexico. Bot. Mar. 54:269-92.

547 McIvor, L., Maggs, C.A., Provan, J. \& Stanhope, M.J. 2001. rbcL sequences reveal 548 multiple cryptic introductions of the Japanese red alga Polysiphonia harveyi. Mol. Ecol. 10: 911-9.

550 Nosil, P., Funk, D.J. \& Ortiz-Barrientos, D. 2009. Divergent selection and 551 heterogeneous genomic divergence. Molec. Ecol. 18:375-402.

552 Palumbi, S.R. 1994. Genetic divergence, reproductive isolation, and marine speciation. 553 Annu. Rev. Ecol Syst. 25:547-72.

554 Payo, D.A., Leliaert, F., Verbruggen, H., D’hondt, S., Calumpong, H. P. \& De Clerck, 555 O. 2013. Extensive cryptic species diversity and fine-scale endemism in the marine red 556 alga Portieria in the Philippines. Proc. R. Soc. Lond. B Biol. Sci. 280: 20122660.

557 Provan, J., Booth, D., Todd, N.P., Beatty, G.E. \& Maggs, C.A. 2008. Tracking 558 biological invasions in space and time: elucidating the invasive history of the green alga 559 Codium fragile using old DNA. Divers. Distributions 14:343-54. 

geography and life history traits on genetic differentiation in benthic marine fishes.

563 Santelices, B. 1990. Patterns of reproduction, dispersal and recruitment in seaweeds.

564 Oceanogr. Mar. Biol. Ann. Rev. 28:177-276.

565 Saunders, G.W. \& McDevit, D.C. 2012. Methods for DNA Barcoding Photosynthetic 566 Protists Emphasizing the Macroalgae and Diatoms. In Kress, W. \& Erickson, D. [Eds.]

567 DNA Barcodes. Methods in Molecular Biology (Methods and Protocols). Humana 568 Press, Totowa, NJ, USA, pp. 207-22

569 Saunders, G.W. \& Moore, T.E. 2013. Refinements for the amplification and sequencing 570 of red algal DNA barcode and RedToL phylogenetic markers: a summary of current 571 primers, profiles and strategies. Algae 28:31-43.

572 Savoie, A. M. \& Saunders, G. W. 2015. Evidence for the introduction of the Asian red 573 alga Neosiphonia japonica and its introgression with Neosiphonia harveyi (Ceramiales, 574 Rhodophyta) in the Northwest Atlantic. Mol. Ecol. 24:5927-37.

575 Savoie, A.M. \& Saunders, G.W. 2016. A molecular phylogenetic and DNA barcode 576 assessment of the tribe Pterosiphonieae (Ceramiales, Rhodophyta) emphasizing the 577 Northeast Pacific. Botany 94: 917-39.

578 Schneider, C.W., Quach, P.K. \& Lane, C.E. 2017. A case for true morphological 579 crypsis: Pacific Dasya anastomosans and Atlantic D. cryptica sp. nov. (Dasyaceae, 580 Rhodophyta). Phycologia 56:359-68.

581 Stamatakis, A. 2014. RAxML version 8: a tool for phylogenetic analysis and post582 analysis of large phylogenies. Bioinformatics 30:1312-13.

583 Straub, S.C., Thomsen, M.S. \& Wernberg, T. 2016. The dynamic biogeography of the 584 anthropocene: the speed of recent range shifts in seaweeds. In Hu, Z.-M. \& Fraser, C. 585 [Eds.] Seaweed Phylogeography. Springer, Amsterdam, pp. 63-93.

586 Thomsen M.S., Wernberg T., South P.M. \& Schiel D.R. 2016. Non-native seaweeds 587 drive changes in marine coastal communities around the world. In Hu, Z.M. \& Fraser, 588 C.I. [Eds.] Seaweed phylogeography. Springer, Dordrecht, pp. 147-185. 
589

590

591

592

593

594

595

596

597

598

599

600

601

602

603

604

605

606

607

608

609

610

611

612

613

614

615

616

617

618

Verbruggen, H. 2014. Morphological complexity, plasticity, and species diagnosability in the application of old species names in DNA-based taxonomies. J. Phycol. 50:26-31.

Voisin, M., Engel, C.R. \& Viard. F. 2005. Differential shuffling of native genetic diversity across introduced regions in a brown alga: Aquaculture vs. maritime traffic effects. Proc. Natl. Acad. Sci. USA 102:5432-7.

Waters, J.M., Fraser, C.I. \& Hewitt, G.M. 2013. Founder takes all: density-dependent processes structure biodiversity. Trends Ecol. Evol. 28:78-85.

Williams, S.L. \& Smith, J.E. 2007. A global review of the distribution, taxonomy, and impacts of introduced seaweeds. Annu. Rev. Ecol. Evol. Syst. 38:327-59.

Womersley, H.B.S. 2003. The marine benthic flora of southern Australia - Part IIID Ceramiales - Delesseriaceae, Sarcomeniaceae, Rhodomelaceae. Australian Biological Resources Study and State Herbarium of South Australia, Canberra and Adelaide, 533 pp.

Won, B.Y., Cho, T.O. \& Fredericq, S. 2009. Morphological and molecular characterization of species of the genus Centroceras (Ceramiaceae, Ceramiales), including two new species. J. Phycol. 45:227-50.

Zuccarello, G., West, J. \& King, R. 1999. Evolutionary divergence in the Bostrychia moritziana/B. radicans complex (Rhodomelaceae, Rhodophyta): molecular and hybridization data. Phycologia 38:234-44.

Zuccarello, G.C., Sandercock, B. \& West, J.A. 2002a. Diversity within red algal species: variation in world-wide samples of Spyridia filamentosa (Ceramiaceae) and Murrayella periclados (Rhodomelaceae) using DNA markers and breeding studies. Eur. J. Phycol. 37:403-18.

Zuccarello, G. C., West, J. \& Rueness, J. 2002b. Phylogeography of the cosmopolitan red alga Caulacanthus ustulatus (Caulacanthaceae, Gigartinales). Phycol. Res. 50:16372.

Zuccarello, G.C. \& West, J. 2003. Multiple cryptic species: molecular diversity and reproductive isolation in the Bostrychia radicans/B. moritziana complex (Rhodomelaceae, Rhodophyta) with focus on North American isolates. J. Phycol. 39:948-59.

This article is protected by copyright. All rights reserved 
Zuccarello, G.C., West J. A. \& Kamiya, M. 2018. Non-monophyly of Bostrychia simpliciuscula (Ceramiales, Rhodophyta): Multiple species with very similar morphologies, a revised taxonomy of cryptic species. Phycological Res. 66:100-7.

\section{Figure legends \\ Figure legends}

Figure 1 Distribution and UPGMA unrooted distance phylogram based on $r b c \mathrm{~L}$ sequences of (a, b) Ophidocladus simpliciusculus, (c, d) Lophosiphonia obscura (as Polysiphonia hemisphaerica and P. boldii in Norway and Texas, respectively, see Appendix S1), and (e, f) P. villum. In panels a, c and e, circles indicate the regions from which sequences are available and their colors indicate the distribution of haplotypes. Areas outlined in red are regions where the species is recorded for the first time. Coastline in black shows the reported distribution (Guiry and Guiry 2018). In panel c, black coastlines represent the recorded distribution of Lophosiphonia obscura, red line $P$. hemisphaerica and yellow line $P$. boldii. Scale bars: $5 \mathrm{~mm}$ in (a), $8 \mathrm{~mm}$ in (c), $6 \mathrm{~mm}$ in (e).

Figure 2 Distribution and UPGMA unrooted distance phylogram based on $r b c \mathrm{~L}$ sequences of (a, b) Polysiphonia devoniensis (as P. kaprauni in North Carolina), (c, d) Symphyocladia dendroidea and (e, f, g) S. spinifera/Xiphosiphonia pennata/X. pinnulata. Symbols are as in Figure 1, and pie divisions in panels a, c and e indicate proportions of each haplotype when multiple haplotypes were present. In panel e, circles with white border correspond to $S$. spinifera and the ones with black border to $X$. pinnulata. Encircled areas marked with red color are regions where the species are here recorded for the first time. In panel a, black lines represent the recorded distribution of $P$. devoniensis and red line the distribution of $P$. kapraunii. In panel c, black lines represent the recorded distribution of $S$. dendroidea, blue lines the regions where it was recorded as $S$. tanakae, red line the region where molecular data demonstrated that $S$. dendroidea 2 is present, the asterisk indicates the area where both S. dendroidea 2 and S. tanakae were reported based on molecular data, and plus symbols the regions from which sequences of $S$. dendroidea 2 are available. In panel e, black lines represent the recorded distribution of $X$. pennata; yellow lines the regions where molecular data showed the presence of $S$. spinifera instead X. pennata, red lines regions where only $X$. pinnulata has been recorded based on molecular data and blue line the region where 
651 both $X$. pinnulata and X. pennata have been recorded based on molecular data. Scale

652 bars: $6 \mathrm{~mm}$ in (a), $7 \mathrm{~mm}$ in (c), $4 \mathrm{~mm}$ in (e).

653 Figure 3 Distribution of Herposiphonia tenella. Asterisks indicate the regions from

654 which sequences are available. Scale bar: $1 \mathrm{~mm}$.

655 Figure 4 RAxML tree based on $r b c \mathrm{~L}$ sequences of the genus Herposiphonia. Samples

656 that morphologically correspond with Herposiphonia tenella are in bold. Bootstrap

657 values are indicated on the nodes when > 80. BE (Belize), CA (Canada), CI (Canary

658 Islands), FR (France), IN (India), IT (Italy), KO (Korea), NC (North Carolina), PO

659 (Portugal), QL (Queensland), SP (Spain), WA (Western Australia), VIC (Victoria).

660

661 Appendix S1. Taxonomic notes.

662 Table S1. GenBank accession numbers of the $r b c \mathrm{~L}$ sequences included in the UPGMA 663 and phylogenetic analysis.

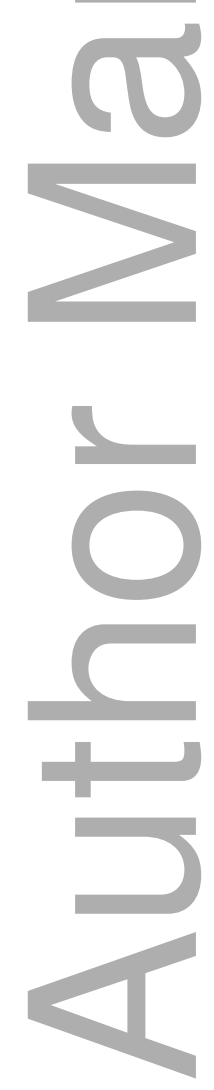

This article is protected by copyright. All rights reserved 


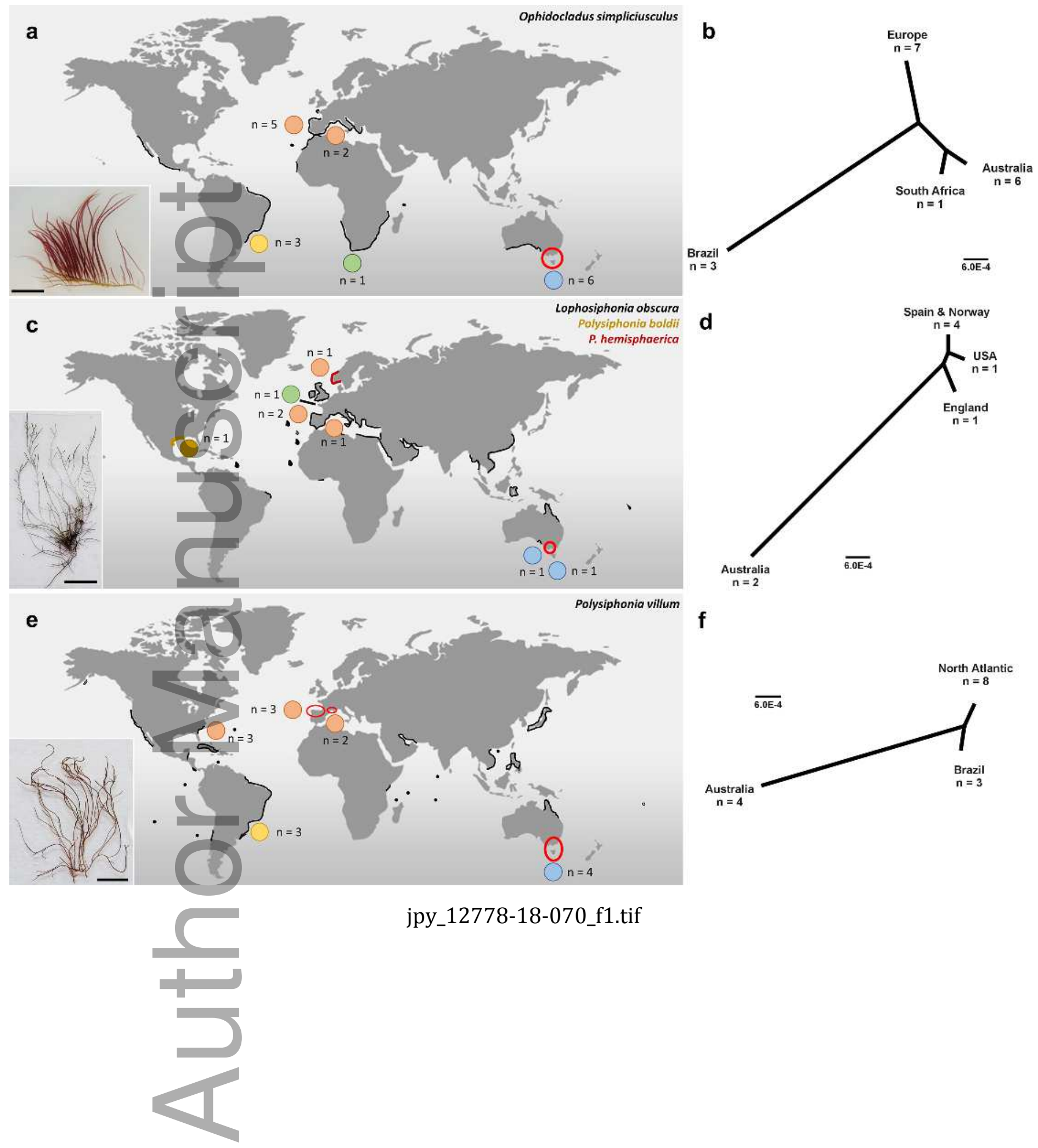

This article is protected by copyright. All rights reserved 


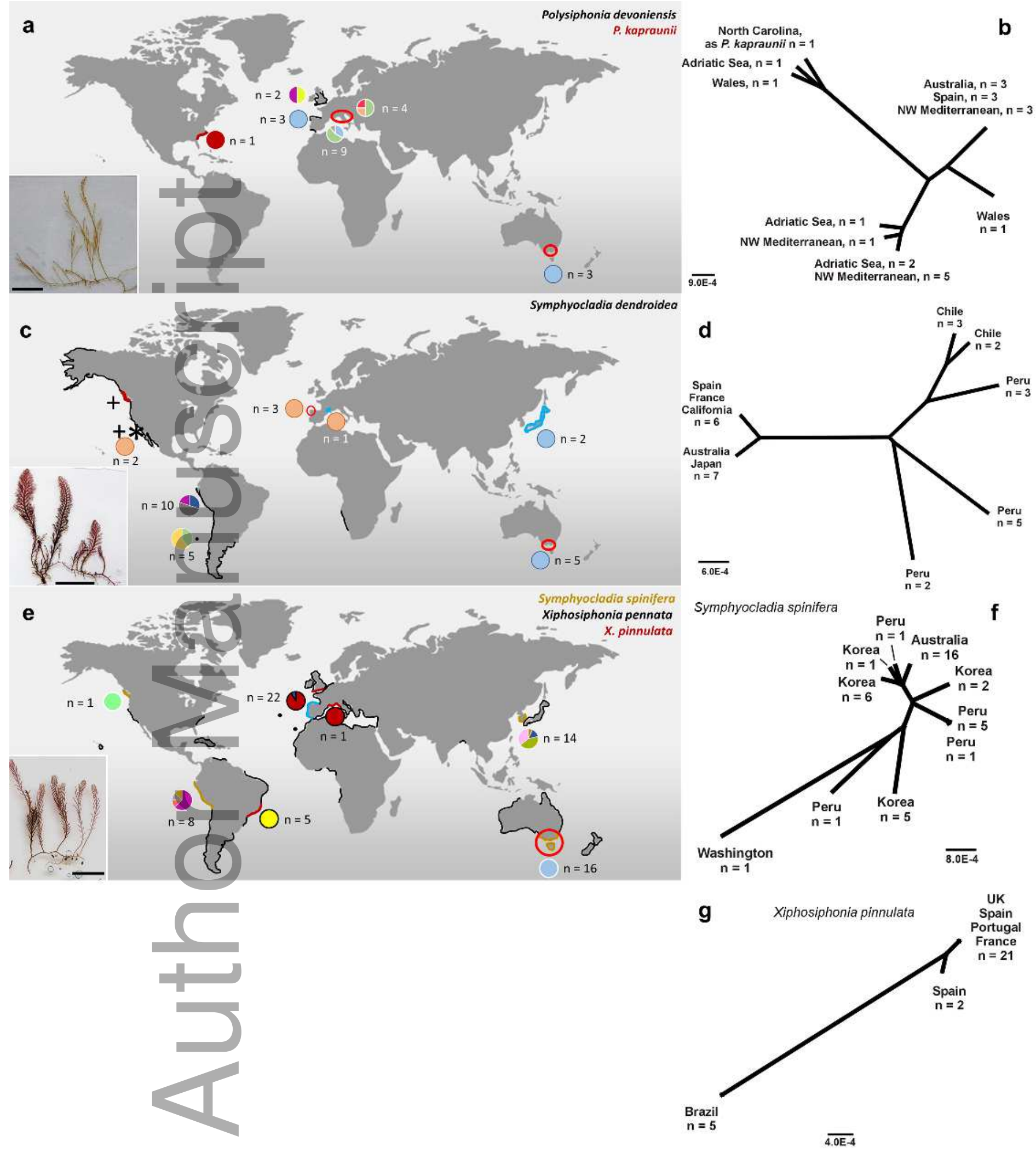

jpy_12778-18-070_f2.tif 

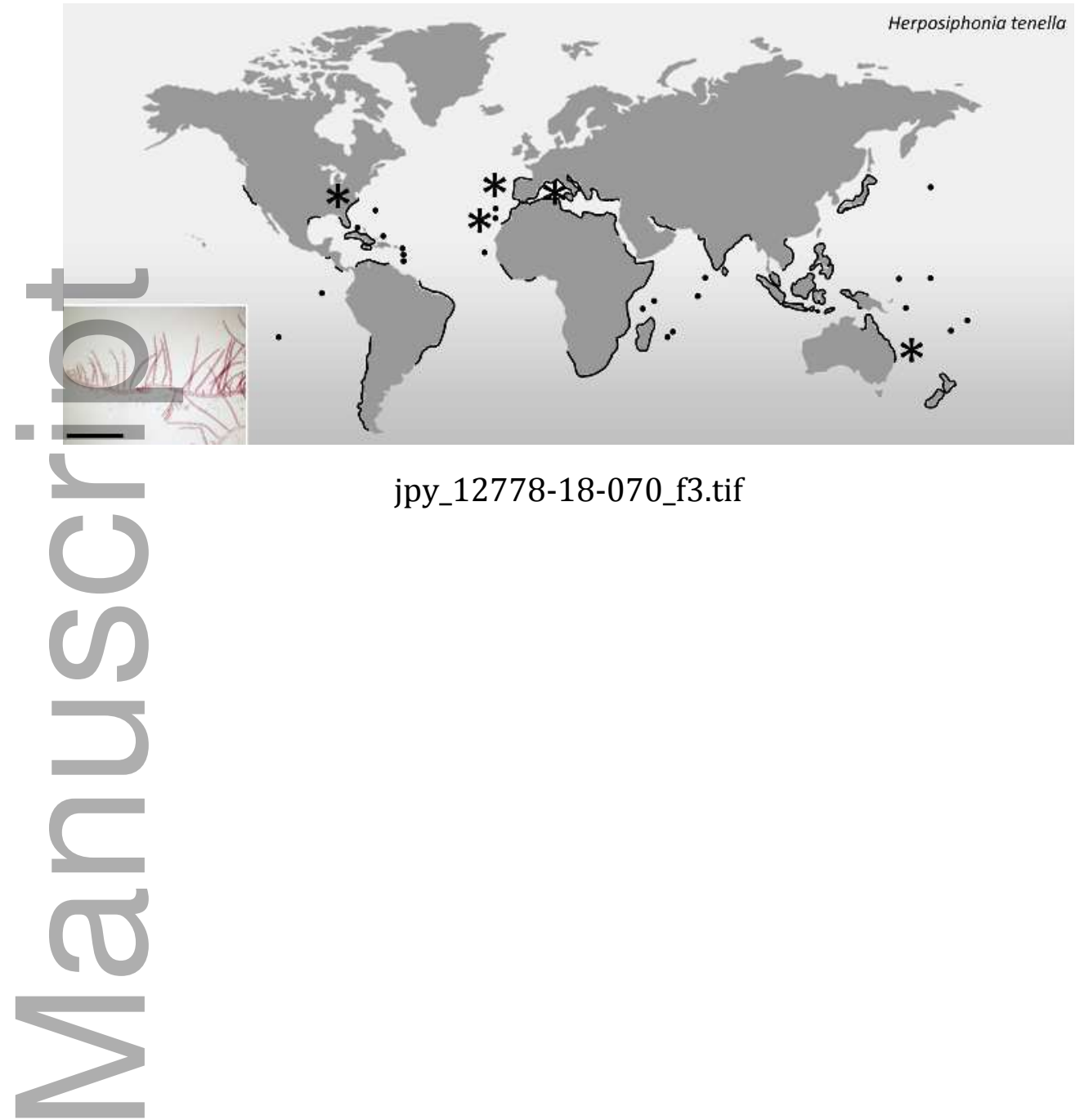

jpy_12778-18-070_f3.tif

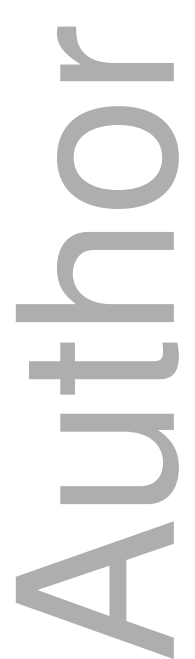

This article is protected by copyright. All rights reserved 
jpy_12778-18-070_f4.pdf

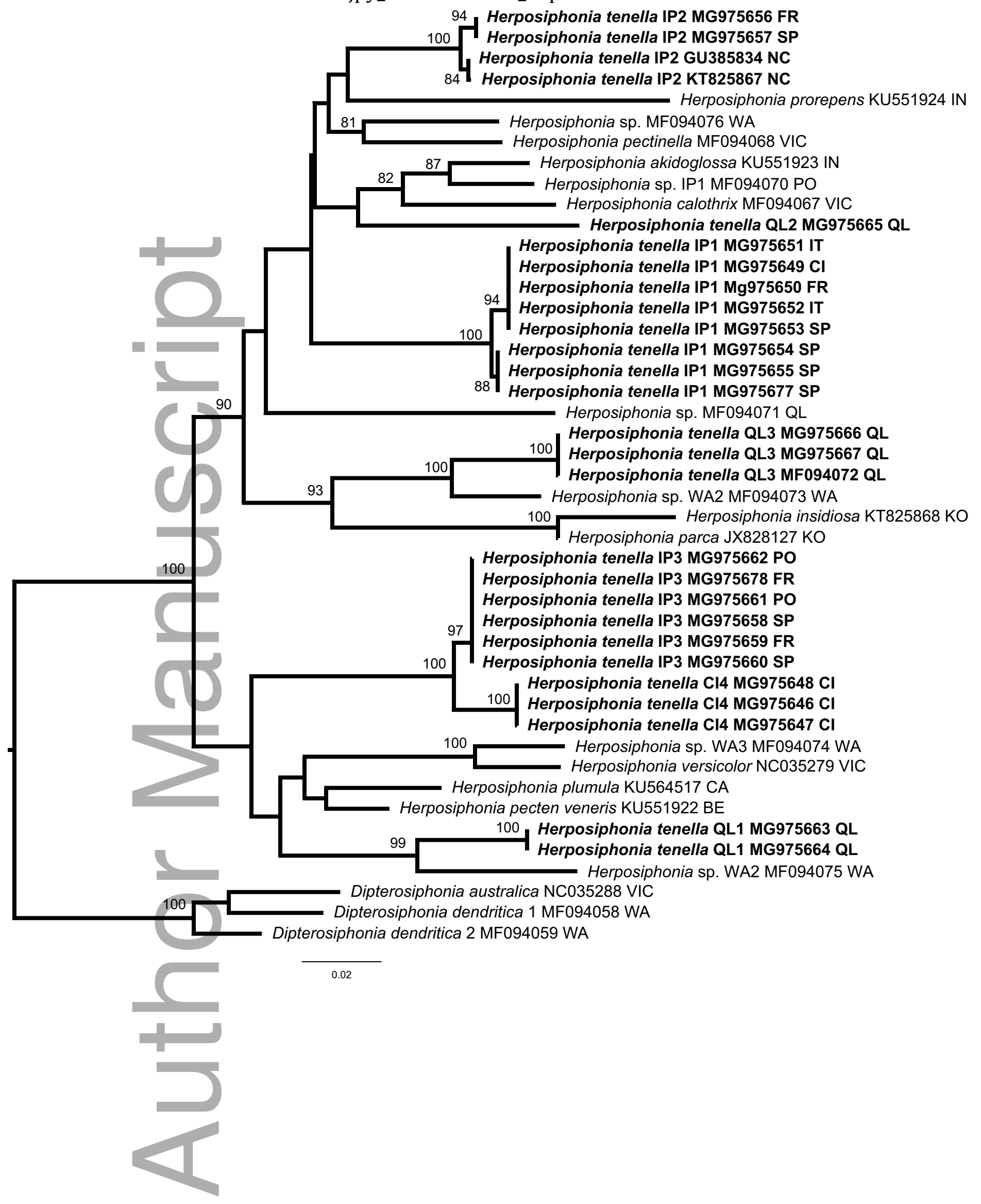

This article is protected by copyright. All rights reserved 


\section{University Library}

\section{- M M I N E R VA \\ A gateway to Melbourne's research publications}

Minerva Access is the Institutional Repository of The University of Melbourne

Author/s:

Diaz-Tapia, P;Maggs, CA;Macaya, EC;Verbruggen, $\mathrm{H}$

Title:

Widely distributed red algae often represent hidden introductions, complexes of cryptic species or species with strong phylogeographic structure

Date:

2018-12-01

\section{Citation:}

Diaz-Tapia, P., Maggs, C. A., Macaya, E. C. \& Verbruggen, H. (2018). Widely distributed red algae often represent hidden introductions, complexes of cryptic species or species with strong phylogeographic structure. JOURNAL OF PHYCOLOGY, 54 (6), pp.829-839. https:// doi.org/10.1111/jpy. 12778.

Persistent Link:

http://hdl.handle.net/11343/284397 